\title{
La inserción de las personas con discapacidad en el empleo público. Análisis jurídico- económico de la situación en la Comunidad de Madrid
}

\section{María Burzaco Samper y Alberto Colino Fernández}

RESUMEN: Las personas con discapacidad sufren dificultades de acceso al mercado de trabajo que exigen políticas públicas de protección y mecanismos específicos que favorezcan la inserción laboral. Este trabajo se centra en los instrumentos de acceso al empleo en el sector público, sus principios, características (distintas de las del sector privado), así como los problemas que plantea para las personas con discapacidad.

En España, la normativa -básica estatal y desarrollo normativo autonómico- es poco ambiciosa y prácticamente limita las medidas positivas al cupo de reserva, consistente en que un porcentaje de las plazas convocadas se reservan a personas con discapacidad. Los conflictos judiciales muestran que esta medida de acción positiva debe conciliarse con los principios de mérito y capacidad que presiden el acceso al empleo público. Los datos demuestran que la rigidez del sistema está suponiendo que el cupo no se cumpla en la práctica.

Por lo demás, este estudio toma como referencia de su análisis el III Plan de Acción de la Comunidad de Madrid: la experiencia de esta Administración en planes plurianuales y de carácter multisectorial permite examinar si las políticas públicas contenidas en estos planes son efectivos y qué aspectos deberían mejorarse para lograr resultados óptimos.

PALABRAS CLAVE: Discapacidad, empleo público, políticas públicas, sector público, discriminación positiva.

CLAVES ECONLIT: H83, J38, J78, J88, K23.

Cómo citar este artículo / How to cite this article: BURZACO, M. \& COLINO, A. (2017): "La inserción de las personas con discapacidad en el empleo público. Análisis jurídico-económico de la situación en la Comunidad de Madrid", CIRIEC-España, Revista de Economía Pública, Social y Cooperativa, 91, $203-234$.

Correspondencia: Dra. María Burzaco Samper, profesora Agregada de Derecho Administrativo, Universidad Pontificia Comillas-ICADE, e-mail: mburzaco@ icade.comillas.edu; Dr. Alberto Colino Fernández, profesor Colaborador Asistente de Economía, Universidad Pontificia Comillas-ICADE, acolino@icade.comillas.edu. 


\section{EXPANDED ABSTRACT}

\section{Labor insertion of people with disabilities in public employment. Legal-economic analysis of the situation in the Community of Madrid}

Disabled people face difficulties when accessing the labour market and then require of public policies to protect them and specific mechanisms to favor their labour market integration. This article focuses on the analysis of the available tools to access public employment, their principles, characteristics (different from those relative to the private sector) and the problems they pose to disabled people.

Employment is the main channel through which disabled people achieve not only personal autonomy, but also social inclusion. Several international reports - among which are paramount the Convention on the Rights of Persons with Disabilities approved by United Nations in 2006 and the European Disability Strategy 2010-2020 — show the vulnerability of this group that suffers from poverty indexes above the average. This is mainly the consequence of their difficulties to find a job.

Within the public policies framework, different mechanisms have been devised to foster the employability of disabled people. Nonetheless, such mechanisms differ between private and public sectors, with the latter being the motivation for this article.

In Spain, the study of this issue consists on the following factors:

a) Firstly, the competential factor, since the legislation is distributed between the Government and the Autonomous Communities. Thus, the latter have margin to implement their own policies on this matter, but complying with governmental principles.

b) According to the Spanish Constitution, the accessing system to public employment is based on merit and ability, which gives way to rigid systems to access public employment (public examination, contest and public examination contest).

Measures to boost public employment of disabled people must comply with those principles and systems taking into account potential limitations.

c) The procedure to facilitate access of disabled people to public employment is the so called "cupo de reserva" (reserved quota), which consists of reserving a percentage of the offered vacancies. This mechanism has also been a source of judicial conflicts given its discriminatory nature, even though eventually endorsed by its characteristic as a positive action aimed to eliminate obstacles for this vulnerable group.

d) Finally, it cannot be forgotten that public sector employment does not only affect territorial 


\section{LA INSERCIÓN DE LAS PERSONAS CON DISCAPACIDAD EN EL EMPLEO PÚBLICO. ANÁLISIS JURÍDICO-ECONÓMICO DE LA SITUACIÓN EN LA COMUNIDAD DE MADRID}

Administrations, but also the so called institutional public sector which consists on several organizations of different nature and legal status with civil servants or contract basis employees. Among these organizations, public firms must comply with the same rules as private companies and, more precisely, they must employ $2 \%$ of disabled people among their workers for companies of more than 50 workers.

This article performs a data analysis that highlights that public firms do not comply with this rule to a larger extend than private companies.

Within this framework, the work focuses its investigation in the Autonomous Community of Madrid because of two main reasons: 1) On the one hand, because this Autonomous Community has been largely implementing multiyear and multisector plans to tackle different issues that affect disabled people. A trip throughout these plans highlights the evolution of public policies regarding this issue and their limitations according to their assessment reports; 2) On the other hand, because of the importance of the Autonomous Community of Madrid in terms of population and economic activity, since Madrid has a great amount of disabled people in the position of obtaining a job.

The relevance of this work is fourfold:

a) Firstly, because it brings together the legislative and economic analyses, allowing not only to depict the departing point but to illustrate with data some of the weaknesses pointed out by the examination of the legal issues.

b) Secondly, the lack of complete official databases throughout this investigation has required of great effort of data collection and elaboration.

c) Thirdly, public policies entail public expenditures of which effectiveness and efficiency should be assessed. This is even more relevant when undertaking multiyear plans prolonged along time. Regarding this, the following Action Plan of the Autonomous Community of Madrid to be undertaken should improve certain elements that this work illustrates.

d) Finally, it suggests original ideas with respect to areas of improvement according to the available data. In this point, the main conclusions of the article are as follows:

1) Public policies regarding the access to public employment of disabled people tend to be limited to comply with the regulation. Such compliance is purely formal and constrained to the reserved quota. Nevertheless, data show that the quota is not fulfilled in practice, and no information is available regarding the reasons for this.

2) The legislation should be oriented differently in diverse fronts: access systems (their characteristics make them particularly burdensome for disabled people), structural vision of the professional career of public servants (i.e. taking into account not only access, but also individual needs of disabled people), training plans... 
3) Any design of public policies on this issue requires of available data to check the plans effectiveness and deadweight loss. Previous assessment (in order to set the needs to be attacked by the plans) and posterior (regarding plans' accomplishment) are essential elements. In this sense, the Third Action Plan of the Autonomous Community of Madrid shows that public employment is integrated in itself but with flaws that make not viable an in depth action with real effects.

4) Access to public employment of disabled people cannot be detached from other components with transversal nature, in particular education/training without which it is not possible to comply with the principles of merit and ability.

KEYWORDS: Disability, public employment, public policies, public sector, positive discrimination. 


\section{Introducción'}

Si el empleo es el principal cauce de integración social ya que favorece la autonomía personal y la integración social, en la actualidad la seguridad ligada al mismo ha quebrado2. La creciente flexibilidad laboral o las dificultades de acceso al mercado de trabajo son factores que la crisis económica ha acrecentado. Esta realidad es aún más desalentadora para determinados colectivos que, por sus circunstancias vitales, presentan dificultades adicionales. Tal es el caso de las personas con discapacidad (PcD), cuya integración laboral requiere, sin duda, de actuaciones públicas tuitivas de diverso signo.

Nuestro análisis se centra en las políticas públicas destinadas al fomento del empleo público, parcela que presenta perfiles propios por los instrumentos de los que se vale que, además, deben compatibilizarse con los principios de acceso a la función pública constitucionalmente establecidos.

Finalmente, examinaremos en particular el caso de la Comunidad de Madrid (CAM) porque esta Comunidad Autónoma lleva un cierto recorrido en el diseño de planes multisectoriales, en los que, de manera integrada, trata de diseñar las políticas que afectan a las PcD. El estudio de los resultados de estos planes permite verificar las deficiencias de algunas políticas públicas y, sobre todo, su eficacia real.

\section{Personas con discapacidad y acceso al empleo en el sector público: cuestiones previas}

2.1. Las políticas públicas de fomento del empleo de personas con discapacidad. Su justificación desde las cifras

Cualquier política de fomento del empleo de colectivos desfavorecidos parte indefectiblemente de la necesidad de superar la fragilidad de su posición de partida. Dicha debilidad es fácilmente verificable en los datos que, de manera tozuda, dibujan un escenario desalentador. Así, los datos mostrados en la Tabla 1, y referentes a la economía española en el año 2015, hacen patente que sigue existiendo una menor presencia de las PcD en el mercado laboral.

1.- Este trabajo se enmarca en el Proyecto de Investigación "Madrid sin barreras: discapacidad e inclusión social" financiado por la Comunidad de Madrid (H2015/HUM3330).

2.- Bengoechea, M.A., Burzaco, M., Carrillo, D., Colino, A., Ramos, J. y Rey, J.L., 2016: 5-6. 


\section{Tabla 1. Tasas de actividad, empleo y paro (porcentajes)}

\begin{tabular}{|l|ccc|ccc|ccc|}
\hline & \multicolumn{3}{|c|}{$\begin{array}{c}\text { Personas con } \\
\text { Discapacidad }\end{array}$} & \multicolumn{3}{c|}{$\begin{array}{c}\text { Personas } \\
\text { sin Discapacidad }\end{array}$} & \multicolumn{3}{c|}{ Total } \\
& Varones & Mujeres & Ambos & Varones & Mujeres & Ambos & Varones & Mujeres & Ambos \\
\hline Tasa de Actividad & 34,4 & 33,1 & 33,9 & 84,2 & 72,0 & 78,1 & 80,9 & 70,0 & 75,5 \\
Tasa de Empleo & 23,8 & 22,8 & 23,4 & 66,9 & 55,1 & 60,9 & 64,0 & 53,4 & 58,7 \\
Tasa de Paro & 30,9 & 31,1 & 31,0 & 20,6 & 23,5 & 21,9 & 20,9 & 23,7 & 22,2 \\
\hline
\end{tabular}

FUENTE: INE. El empleo de las personas con discapacidad ${ }^{3}$.

Como se puede observar, las PcD muestran tasas de actividad muy inferiores a las del resto de la población. Esto supone una escasa participación de este colectivo en el mercado de trabajo. Así, en el año 2015, solo una de cada tres PcD en edad de trabajar estaban o bien ocupadas o paradas, pero buscando activamente empleo. Esto contrasta con la cifra de personas sin discapacidad, cuyo porcentaje se situaba en el $78,1 \%$.

A este factor hay que añadir las elevadas tasas de paro de este colectivo (31\%), que son indicativas de las dificultades para acceder a un puesto de trabajo. Las cifras muestran que de aquellas PcD que buscan activamente empleo, aproximadamente un tercio, no lo había encontrado. Esta tasa superaba en más de 9 puntos porcentuales a la correspondiente al resto de la población.

Del mismo modo, la tasa de empleo de las PcD revela la escasa ocupación dentro de este colectivo. Así, menos de una de cada cuatro personas en edad de trabajar lo estaba haciendo en el año 2015. Esta cifra contrasta con la de las personas sin discapacidad, donde casi dos de cada tres personas en edad de trabajar estaban efectivamente ocupadas.

Atendiendo a los datos mostrados, es evidente que las PcD encuentran mayores trabas para lograr un puesto de trabajo y que su empleo es de peor calidad4 4 .

3.- El Empleo de las PCD es una operación de periodicidad anual que tiene como objetivo obtener datos sobre la fuerza de trabajo (ocupados y parados) y la población ajena al mercado laboral (inactivos) dentro del colectivo de personas con edades comprendidas entre los $16 \mathrm{y}$ 64 años que poseen certificado de discapacidad.

La operación es fruto de un convenio de colaboración entre INE, el IMSERSO, la Dirección General de Coordinación de Políticas Sectoriales sobre Discapacidad, el Comité Español de Representantes de Personas con Discapacidad (CERMI) y la Fundación ONCE. En su realización se utiliza la información procedente de la integración de los datos de la Encuesta de población activa (EPA) con los datos administrativos registrados en la Base de Datos Estatal de Personas con Discapacidad (BEPD), que proporciona información sobre las características de los ciudadanos que han sido reconocidos oficialmente como personas con discapacidad. El empleo de las personas con discapacidad se elabora a partir de una muestra, razón por la que no se pueden proporcionar resultados detallados para todas las Comunidades Autónomas españolas, solo para aquellas en que la muestra sea representativa.

4.- En España, Observatorio de Discapacidad, 2015: 249 y ss; 2016: 195 y ss; más detalladamente, ODISMET, 2016 y 2017. 


\section{LA INSERCIÓN DE LAS PERSONAS CON DISCAPACIDAD EN EL EMPLEO PÚBLICO. ANÁLISIS JURÍDICO-ECONÓMICO DE LA SITUACIÓN EN LA COMUNIDAD DE MADRID}

Sin entrar ahora en los motivos, interesa poner de relieve que ese hándicap explica las obligaciones impuestas a los Estados para la implementación de políticas públicas que traten de eliminar tales barreras. Así:

a) La Convención de los Derechos de Personas con Discapacidad aprobada por Naciones Unidas el 13 de diciembre de $2006^{5}$ impone a los Estados parte "Emplear a personas con discapacidad en el sector público" (art. $27.1 \mathrm{~g}$ ), como mención aparte de las obligaciones de puesta en marcha de medidas promocionales dirigidas específicamente al sector privado.

b) La Estrategia Europa $2020^{6}$ hace referencia expresa a las personas con discapacidad en su iniciativa emblemática "Plataforma europea contra la pobreza", lo cual es, en sí mismo, revelador de su condición de grupo vulnerable que padece "riesgos particulares" (p. 24). En este punto las políticas de empleo como cauce de integración y cohesión adquieren un protagonismo indiscutible (Anexo 1, p. 37).

c) Ahondando en lo anterior, la Estrategia Europea sobre Discapacidad 2010-20207 recuerda que una sexta parte de la población europea sufre una discapacidad entre leve y grave y que las PcD "registran un índice de pobreza un $70 \%$ superior a la media, en parte por tener un menor acceso al empleo"8. Desde esta cifra, huelga justificar que el empleo sea uno de los ocho ámbitos de actuación.

2.2. Empleo público: principios de mérito y capacidad y sistemas de acceso. Las dificultades de su traslación a las personas con discapacidad

El acceso al empleo por parte de PcD está marcado por una serie de instrumentos que, finalmente, tratan de coadyuvar a la superación de los obstáculos de origen que sufre este colectivo. Dichos instrumentos difieren según estemos en el sector público o en el sector privado, en el bien entendido que también el primero requiere de importantes matices en el caso del sector público institucional.

El concepto de empleo público, más amplio que el de función pública, recoge la variada tipología enunciada en el art. 8 Real Decreto Legislativo 5/2015, de 30 de octubre, por el que se aprueba el texto refundido de la Ley del Estatuto Básico del Empleado Público (EBEP), de suerte que son empleados públicos "quienes desempeñan funciones retribuidas en las Administraciones Públicas al servicio de los intereses generales", clasificándose en cuatro categorías, a saber: a) funcionarios de carrera; b) funcionarios interinos; c) personal laboral, que puede ser fijo, por tiempo indefinido o temporal; y d) personal eventual (arts. 9 a 12 EBEP, respectivamente).

5.- Instrumento de Ratificación publicado en BOE núm. 96, de 21 de abril de 2008. Disponible en: https://www.boe.es/boe/dias/2008/04/21/pdfs/A20648-20659.pdf

6. - Comunicación de la Comisión "Europa 2020: Una estrategia para un crecimiento inteligente, sostenible e integrador" [COM (2010) 2020 final] Disponible en: $h$ ttp://eur-lex.europa.eu/legal-content/ES/TXT/PDF/?uri=CELEX:52010DC2020\&from=ES

7.- Comunicación de la Comisión al Parlamento Europeo, al Consejo, al Comité Económico y Social Europeo y al Comité de las Regiones "Estrategia Europea sobre Discapacidad 2010-2020: un compromiso renovado para una Europa sin barreras" [COM (2010) 636 final]: Puede consultarse en: http://eur-lex.europa.eu/legal-content/ES/TXT/?uri=celex:52010DC0636

8.- Sobre el gasto público que ello comporta, véase Murgui, S. \& Dasi, R.M., 2017. 
Es sabido que el acceso a la función pública está presidido por los principios de mérito y capacidad (arts. 103.3 CE y 1.3 b) EBEP), circunstancia que se traduce en los sistemas de acceso (oposición, concurso y concurso-oposición ${ }^{9}$ ) y marca definitivamente cualquier política que trate de privilegiar a las PcD. En sentido, apuntaremos los aspectos más relevantes de manera sintética:

a) En nuestro Estado compuesto no puede eludirse la cuestión competencial. Así en materia de empleo público de $\mathrm{PCD}$ al Estado le corresponde establecer la legislación básica del régimen estatutario de los funcionarios (art. 149.1.18 CE), en conexión, asimismo, con los apartados 7 (legislación laboral) y 13 (bases y coordinación de la planificación general de la actividad económica) del mismo art. 149.1 CE.

Traducido al empleo público de las $\mathrm{PCD}$, ello implica que las bases recogidas en el actual art. 59 EBEP ${ }^{10}$ son de respeto obligado para las Comunidades Autónomas. Si bien estas, en la medida en que puedan dictar la normativa de desarrollo de la legislación básica en la materia, podrán prever medidas más favorables al "núcleo duro indisponible" recogido en el mencionado precepto.

De la lectura del art. 59 EBEP se desprende que el fomento del empleo público para PcD se centra, casi en exclusiva, en el llamado cupo de reserva, que, como su propia denominación indica, consiste en reservar o retener un porcentaje de las plazas convocadas para PcD. La cifra del cupo ha ido incrementándose en el tiempo hasta alcanzar actualmente el $7 \%{ }^{11}$. De ese porcentaje, al menos el

9.- La determinación del sistema aplicable no es enteramente libre. Como establece el art. 60.6 EBEP los sistemas selectivos de funcionarios de carrera serán los de oposición y concurso-oposición, siendo excepcional el concurso (que requiere habilitación por ley). De igual modo, en relación con el personal laboral fijo, el art. 60.7 EBEP, aunque en este caso la dicción de la ley parece posibilitar que se opte por el concurso de méritos sin las restricciones señaladas para los funcionarios de carrera.

Queda fuera de esta consideración el personal eventual que, en cuanto realiza funciones de asesoramiento y confianza, es de designación y cese discrecional.

10.- Reproducimos el contenido del art. 59 EBEP para que algunas referencias que haremos con posterioridad se entiendan cabalmente:

"1. En las ofertas de empleo público se reservará un cupo no inferior al siete por ciento de las vacantes para ser cubiertas entre personas con discapacidad, considerando como tales las definidas en el apartado 2 del artículo 4 del texto refundido de la Ley General de derechos de las personas con discapacidad y de su inclusión social, aprobado por el Real Decreto Legislativo 1/2013, de 29 de noviembre, siempre que superen los procesos selectivos y acrediten su discapacidad y la compatibilidad con el desempeño de las tareas, de modo que progresivamente se alcance el dos por ciento de los efectivos totales en cada Administración Pública.

La reserva del mínimo del siete por ciento se realizará de manera que, al menos, el dos por ciento de las plazas ofertadas lo sea para ser cubiertas por personas que acrediten discapacidad intelectual y el resto de las plazas ofertadas lo sea para personas que acrediten cualquier otro tipo de discapacidad.

2. Cada Administración Pública adoptará las medidas precisas para establecer las adaptaciones y ajustes razonables de tiempos y medios en el proceso selectivo y, una vez superado dicho proceso, las adaptaciones en el puesto de trabajo a las necesidades de las personas con discapacidad".

11.- La reserva adquirió una cierta estabilidad desde 1988, año en el que se incorporó una Disposición Adicional 19a en la Ley 30/1984, de 2 de agosto, de Medidas para la reforma de la función pública, previendo que aquella fuera de un $3 \%$ de las vacantes. Se pasó a un $5 \%$ gracias a la reforma realizada por Ley 53/2003, de 10 de diciembre, sobre empleo público de discapacitados (BOE núm. 296, de 11 de diciembre de 2003)

Por su parte, la redacción original del EBEP recogió ese mismo 5\%, que pasó a un 7\% tras la reforma operada por la Ley 26/2011, de 1 de agosto, de adaptación normativa a la Convención Internacional sobre los derechos de las personas con discapacidad (BOE núm. 184, de 2 de agosto de 2011)

Para un estudio más pormenorizado de los antecedentes, Cordero Gordillo, 2012: 145-149; Martínez Hernández, 2009: 34-39; Pérez Pérez, 2015: $482-483$.

CIRIEC-España, Revista de Economía Pública, Social y Cooperativa

ISSN: 0213-8093

№ 91/2017, pp. 203-234 


\section{LA INSERCIÓN DE LAS PERSONAS CON DISCAPACIDAD EN EL EMPLEO PÚBLICO. ANÁLISIS JURÍDICO-ECONÓMICO DE LA SITUACIÓN EN LA COMUNIDAD DE MADRID}

$2 \%$ debe dirigirse a su cobertura por parte de PcD intelectual, previsión que viene a dar respuesta a una reivindicación tenaz de las asociaciones de afectados ${ }^{12}$.

Por lo demás, se señala como objetivo último llegar, al menos, a un $2 \%$ de los efectivos totales de cada Administración lo que, por el momento, no pasa de ser un desiderátum.

Volviendo a la distribución constitucional de competencias, debe indicarse que el porcentaje sentado por la legislación estatal actúa como mínimo, de suerte que las CCAA pueden ampliar tal porcentaje, pero nunca reducirlo. De hecho, alguna Comunidad Autónoma ha establecido un porcentaje superior: vgr. Extremadura, que ha llegado al $10 \%$.

b) La conciliación entre esta medida de fomento del empleo público y los principios de mérito y capacidad no ha sido pacífica. Sin embargo, el Tribunal Constitucional13 han desechado todos los argumentos que tachaban el cupo de discriminatorio, recordando que corresponde a los poderes públicos "promover las condiciones para que la libertad y la igualdad del individuo y de los grupos en que se integra sean reales y efectivas; remover los obstáculos que impidan o dificulten su plenitud y facilitar la participación de todos los ciudadanos en la vida política, económica, cultural y social" (art. 9.2 CE).

No obstante, el cupo exige que se cohoneste con los principios constitucionales de mérito y capacidad, de suerte que las PcD que pretendan acceder a la función pública habrán de someterse a las pruebas que permitan verificar su capacidad, aptitud e idoneidad para desempeñar las funciones que correspondan a las plazas ofertadas. Y ello sin perjuicio de los ajustes que requiera la realización de las pruebas por razón de la discapacidad que pueda padecer el candidato.

c) Debe también aclararse cómo opera el turno relativo al cupo de reserva y el turno libre, cuestión que tampoco ha estado exenta de problemas.

Vaya por delante que la discapacidad remite a un concepto legal de modo que la concurrencia al turno del cupo exige la acreditación de dicha condición. Así, conforme al art. 4.2 Real Decreto Legislativo 1/2013, de 29 de noviembre, por el que se aprueba el Texto Refundido de la Ley General de derechos de las personas con discapacidad y de su inclusión social (LGDIS), tienen la consideración de PcD aquellas a las que se reconozca un grado de discapacidad igual o superior al $33 \%$ y las que el propio precepto asimila a tal situación ${ }^{14}$. Por su parte, el reconocimiento exige una resolución formal que se produce a través del procedimiento administrativo diseñado por el RD 1971/1999, de 23

12.- CERMI, 2011: 2.

13.- Entre otras, STC 269/1994, de 3 de octubre. BOE núm. 267, de 8 de noviembre de 1994.

14.- Nos referimos, en concreto a los "pensionistas de la Seguridad Social que tengan reconocida una pensión de incapacidad permanente en el grado de total, absoluta o gran invalidez, y a los pensionistas de clases pasivas que tengan reconocida una pensión de jubilación o de retiro por incapacidad permanente para el servicio o inutilidad". 
de diciembre, de procedimiento para el reconocimiento, declaración y calificación del grado de discapacidad $^{15}$.

Sin embargo, el hecho de que una persona, en cuanto cumple la citada condición, pueda presentarse al cupo de reserva, no determina la obligación de hacerlo. De este modo, el candidato con discapacidad podrá, libremente, optar entre el turno libre y el cupo de reserva. Téngase en cuenta, además, que la materialización de los principios de mérito y capacidad y la competencia entre candidatos se produce en el seno de cada turno ${ }^{16}$.

d) Para el cumplimiento del cupo de reserva se toma como referencia la oferta global de empleo público, no las convocatorias de los procesos selectivos singularmente consideradas ${ }^{17}$. Debe advertirse que las funciones propias de determinados cuerpos funcionariales son difícilmente compatibles con situaciones de discapacidad (p.ej. Fuerzas y Cuerpos de Seguridad del Estado) y no siempre el número de plazas convocadas permite atender el porcentaje del cupo de manera perfecta ${ }^{18}$.

\subsection{El empleo de las personas con discapacidad en la Administración institucional}

Dejando al margen la disquisición teórica sobre el concepto y extensión del concepto de Administración Pública, no puede desconocerse que junto con los llamados entes territoriales ${ }^{19}$, tenemos un amplio abanico de entes u organismos que integran la conocida como Administración instrumental.

Tales entes gozan de personalidad jurídica propia para el cumplimiento de sus fines, pero son dispares en cuanto a sus funciones, naturaleza, forma y régimen jurídico. Esta realidad compleja ni siquiera es unívoca en todo el territorio nacional, de suerte que el cuadro que presenta la Administración General del Estado no es enteramente igual al existente en las diversas Comunidades Autónomas; y qué decir ya si elevamos la comparativa al ámbito internacional: posiblemente esto explica la ambigüedad con que se pronuncia la OIT (2014: 60-61) cuando habla del sector público por contraposición al sector privado.

15. - BOE núm. 22, de 26 de enero de 2000. Hemos sustituido el término "minusvalía" que rotulaba el RD por el más correcto actualmente de discapacidad. Sobre el procedimiento, Torres López, 2012: 121-126.

16.- Esta circunstancia ha venido avalada por jurisprudencia consolidada que subraya que son modalidades distintas. Su funcionamiento se verifica del siguiente modo: las personas con discapacidad deben someterse al proceso selectivo y tienen que superarlo con el mínimo establecido en la convocatoria. El nombramiento depende ya del contraste de las calificaciones de los aspirantes (recuérdese que la regla general impide que aprueben más aspirantes que plazas convocadas). Entre otras, STS de 18 de octubre de 2007 [EI Derecho Jurisprudencia (EDJ) 2007/195056].

17.- Pérez Pérez, 2015: 489.

18. - Sobre cómo deba hacerse el redondeo no hay una opinión pacífica, aunque algunas normas establecen el modo de solucionar los eventuales "decimales". Concretamente el art. 5.2 del Decreto 54/2006, de 22 de junio, que regula el acceso de las personas con discapacidad a la Administración de la Comunidad de Madrid (BOCM núm. 150, de 26 de junio de 2006) establece que si "resultase una fracción decimal igual o superior a 0,5 se computará como una plaza a incluir en el mismo".

19.- Se incluye en dicha referencia la Administración General del Estado, las Comunidades Autónomas y los Entes Locales (municipios, provincias e islas). 


\section{LA INSERCIÓN DE LAS PERSONAS CON DISCAPACIDAD EN EL EMPLEO PÚBLICO. ANÁLISIS JURÍDICO-ECONÓMICO DE LA SITUACIÓN EN LA COMUNIDAD DE MADRID}

La invariable problemática que estos entes comportan en el Derecho Público se proyecta sobre los diversos sectores en los que operan y en las parcelas que implica su organización: control de sus actos, régimen contractual y patrimonial y, por supuesto, su régimen de personal. Tomando como referencia la tipología que presenta el sector público estatal de acuerdo con la Ley 40/2015, de 1 de octubre, de Régimen jurídico del sector público, el cuadro resultante es el que sigue (LRJSP) 20 :

\begin{tabular}{|c|c|c|}
\hline \multirow{2}{*}{$\begin{array}{l}\text { Personificaciones } \\
\text { Instrumentales }\end{array}$} & $\begin{array}{l}\text { Personificaciones o entes de } \\
\text { naturaleza corporativa } \\
\text { (base asociativa: asociación } \\
\text { de } 2 \text { o más entes públicos) }\end{array}$ & $\begin{array}{l}\text { - Mancomunidades de Municipios } \\
\text { - Consorcios }\end{array}$ \\
\hline & $\begin{array}{l}\text { Personificaciones de naturaleza } \\
\text { fundacional o institucional }\end{array}$ & $\begin{array}{l}\text { ORGANISMOS PÚBLICOS (forma jurídica pública): } \\
\text { - Organismos Autónomos } \\
\text { - Entidades Públicas Empresariales } \\
\text { - Sociedades mercantiles estatales } \\
\text { - Fundaciones Públicas }\end{array}$ \\
\hline $\begin{array}{l}\text { ADMINISTRACIONES } \\
\text { INDEPENDIENTES } \\
\text { (Organismos reguladores) }\end{array}$ & \multicolumn{2}{|c|}{$\begin{array}{l}\text { Entidades que deben desempeñar su actividad con base en criterios de profesionalidad y } \\
\text { neutralidad por incidir: } \\
\text { - En la ordenación y disciplina de sectores económicos capitales (Banco España, Comisión } \\
\text { Nacional de los Mercados y de la Competencia...) } \\
\text { - En el régimen de libertades públicas (Agencia de Protección de Datos) }\end{array}$} \\
\hline
\end{tabular}

Sin perjuicio de los matices que cada uno de estos organismos puede presentar, la cuestión pasa por determinar si su personal es funcionario o laboral (cuando no de ambos tipos dentro de la misma organización) y cómo se cumple la reserva o el cupo de PcD en estos casos.

La propia estadística no lo aclara, ya que cuando se alude al sector público se hace sin distingos de suerte que no sabemos si sólo se toman en consideración empresas públicas o toda la tipología existente, con independencia de si su actividad es empresarial, o más propiamente administrativa.

Indudablemente el régimen jurídico aplicable comporta variaciones: a aquellas que se rijan por Derecho laboral estarán obligadas a cumplir el $2 \%$ previsto para empresas de más de 50 trabajadores (art. 42 LGDIS). Sin embargo, los entes institucionales cuyo personal sea funcionarial, deben respetar la reserva establecida en la normativa administrativa21. Con todo, la realidad no difiere en sustancia no alcanzándose, ni en uno ni en otro caso, los mínimos legales. Los datos mostrados en la Tabla 2 así lo avalan.

20.- BOE núm. 236, de 2 de octubre de 2015. Esquema correspondiente a la Administración General del Estado. Aunque pueden presentar distintas denominaciones, estas tipologías existen igualmente en los ámbitos autonómicos y locales. Junto a las mencionadas en el cuadro adjunto, pueden identificarse también entidades de régimen singular, esto es, organismos que no se ajustan a ninguno de los tipos, siendo su régimen jurídico el establecido en su ley de creación. Asimismo, se suman las Agencias estatales que, creadas bajo el paraguas de la Ley 28/2006, de 18 de julio, de Agencias estatales para la mejora de los servicios públicos (hoy derogada por la LRJSP), queden subsistentes.

Para un examen más concreto de cada uno de estos tipos de entes: Burzaco Samper, 2016.

21.- Pérez Pérez, 2015: 375-378. 


\section{Tabla 2. Asalariados que cotizan en empresas de $>50$ trabajadores, exceptuando Centros Especiales de Empleo, según el porcentaje de PcD de la empresa}

\begin{tabular}{|l|cc|}
\hline & Asalariados & Porcentaje \\
\hline Empresas del Sector Público & & \\
\hline No cumplen la cuota de reserva & 1.422 .200 & 72,9 \\
\hline - Porcentaje 0 & 82.400 & 4,3 \\
- Porcentaje $<2 \%$ & 1.339 .800 & 68,6 \\
\hline Cumplen la cuota de reserva & 530.500 & 27,1 \\
\hline - Porcentaje $>2 \%$ y $<5 \%$ & 436.200 & 22,3 \\
- Porcentaje $>5 \%$ & 94.300 & 4,8 \\
\hline Total & 1.952 .700 & 100,0 \\
\hline Empresas del Sector Privado & & \\
\hline No cumplen la cuota de reserva & 3.458 .500 & 68,7 \\
\hline - Porcentaje 0 & 704.300 & 14,0 \\
\hline - Porcentaje $<2 \%$ & 2.754 .200 & 54,7 \\
\hline Cumplen la cuota de reserva & 1.576 .900 & 31,3 \\
\hline - Porcentaje $>2 \%$ y $<5 \%$ & 925.800 & 18,4 \\
\hline - Porcentaje $>5 \%$ & 651.100 & 12,9 \\
\hline Total & $\mathbf{5 . 0 3 5 . 5 0 0}$ & 100,0 \\
\hline
\end{tabular}

Nota: Los datos se refieren únicamente a asalariados que cotizan a la Seguridad Social y lo hacen en centros ordinarios. Se excluyen los Centros especiales de empleo y a los funcionarios que cotizan a las mutualidades del Estado.

FUENTE: INE. El empleo de las personas con discapacidad.

Los datos muestran que en el año 2015, las empresas del sector público que no cumplían con la cuota de reserva suponían casi el $73 \%$ de las mismas, porcentaje muy superior al que mostraban las empresas del sector privado (68,7\%). Además, de las empresas del sector público que cumplían con la normativa (530.500), la inmensa mayoría lo hacía con porcentajes inferiores al 5\%22.

Esta circunstancia es especialmente criticable: que el sector público cumpla "peor" la normativa que el sector privado, no es de recibo y supone un pésimo ejemplo por parte de quienes deberían estar sirviendo de modelo de inserción laboral para $\mathrm{PcD}$, sin que las razones que parecen esgrimirse sirvan de justificación válida23.

22.- En cuanto a las estadísticas que ofrece la inserción laboral de $P c D$ específicamente en entidades y empresas de la Economía Social, ofrecen resultados reveladores Santero, R., Castro, B., Martínez, I. \& Guilló, N., 2016: 39-55.

23.- Pérez Pérez, 2015: 491, apoyándose en un estudio de Contreras y Guillén, revela que en las encuestas realizadas a gestores de empresas públicas se busca justificación al incumplimiento de la reserva en la falta de concurrencia de personas con discapacidad a los procesos de selección, falta de formación adecuada, ausencia de medios de ayuda adecuados en la empresa, existencia de barreras físicas, entre otras. 


\section{LA INSERCIÓN DE LAS PERSONAS CON DISCAPACIDAD EN EL EMPLEO PÚBLICO. ANÁLISIS JURÍDICO-ECONÓMICO DE LA SITUACIÓN EN LA COMUNIDAD DE MADRID}

La nueva Ley 9/2017, de 8 de noviembre, de Contratos del Sector Público (LCSP) 24 puede servir de acicate en este empeño en la medida en que las empresas públicas pueden concurrir a las licitaciones públicas de Administraciones distintas de las que dependan y en competencia con empresas privadas. Pues bien: se contempla como causa de prohibición para contratar "en el caso de empresas de 50 o más trabajadores, no cumplir el requisito de que al menos el 2 por ciento de sus empleados sean trabajadores con discapacidad' (art. 71.1 d) LCSP); y, en general, subraya el papel de las cláusulas sociales en la contratación pública: vgr. el fomento de la integración social de PcD puede convertirse en criterio de adjudicación del contrato como criterio cualitativo de corte social (art. 145.1. $1^{\circ}$ LCSP); el porcentaje de personal con discapacidad puede actuar como criterio de desempate cuando es superior al mínimo legal (art. 147.1 LCSP); amén de las previsiones específicas sobre condiciones especiales de ejecución (art. 202.2 LCSP), centros especiales de empleo y empresas de inserción, a los que pueden reservarse contratos públicos (Disposición Adicional $4^{\mathrm{a}}$ LCSP), entre otras.

\section{Análisis de la situación en la Comunidad de Madrid}

\subsection{Razones de la elección}

La pertinencia de examinar el acceso al empleo en el sector público en el caso concreto de la Comunidad de Madrid obedece a dos razones fundamentales:

a) Esta Comunidad Autónoma lleva tiempo diseñando planes de carácter plurianual y vocación multisectorial que tratan de abordar los ámbitos que afectan de manera relevante al colectivo de PcD. El recorrido por dichos planes pone de relieve la evolución de las políticas públicas en la materia y sus eventuales deficiencias e imperfecciones, sobre todo a la luz de los informes de evaluación ligados a dichos planes.

b) Por razones evidentes trabadas al número de población, la CAM es una de las Comunidades Autónomas que cuenta con mayor número de $\mathrm{PcD}$ en condiciones de obtener un empleo y la Comunidad Autónoma que concita mayor actividad económica.

Así, la Tabla 3 (Anexo) muestra que a fecha 31 de diciembre de 2014, el número de PcD paradas fue de 143.102, que representan el 3,22\% del total de los parados a nivel estatal. El total de personas del colectivo que demandaron empleo a esa misma fecha ascendió a 222.685; de éstas, el

24.- Hemos abreviado el largo título que rotula esta norma: Ley 9/2017, de 8 de noviembre, de Contratos del Sector Público, por la que se transponen al ordenamiento jurídico español las Directivas del Parlamento Europeo y del Consejo 2014/23/UE y 2014/24/UE, de 26 de febrero de 2014 (BOE núm. 272, de 9 de noviembre de 2017). 
$64,26 \%$ son las que se consideran como paro registrado o demandantes parados, al ser excluidos los colectivos que contempla la norma como no computables ${ }^{25}$ (Informe del mercado de trabajo de las personas con discapacidad estatal, 2015).

Un año más tarde, del total de parados a nivel nacional, las PcD suponían un 3,53\%, continuando con la tendencia ascendente mostrada desde el comienzo de la serie histórica. Este dato es un reflejo de las dificultades de integración de este colectivo en el mercado de trabajo nacional. Como queda patente en la Tabla 3 , el número de $\mathrm{PCD}$ paradas a nivel nacional ha aumentado desde las 80.922 del año 2009 hasta las 144.399 del año 2015, un incremento de casi el 80\%.

De este modo, las PcD demandantes paradas han aumentado su porcentaje sobre el total de personas demandantes paradas de manera continuada desde 2009 en que suponían el 2,06\% de las mismas hasta el 3,53\% del año 2015.

En lo que respecta a la CAM, el número de demandantes de empleo parados con discapacidad aumentó aún con mayor vigor y se duplicó en este periodo, pasando de los 6.707 del año 2009 a los 13.985 del último año para el que se dispone de información. Situándose así como la cuarta Comunidad Autónoma española por número de demandantes de empleo parados, solo por detrás de Andalucía, Cataluña y la Comunitat Valenciana. La correspondiente tasa sobre el total de demandantes parados también se duplicó desde el 1,48\% hasta el 3,09\%.

La reciente Estrategia Madrid por el Empleo 2016-2017 (2016: 18-19) aporta algo más de concreción indicando que de los desempleados que registran alguna discapacidad, el $63,14 \%$ posee discapacidad física, el $24,52 \%$, psíquica y el restante $11,83 \%$, sensorial. Por otro lado, del número total, el $48,63 \%$ son hombres, y el $51,37 \%$, mujeres.

\subsection{Los planes de acción de la CAM: su evolución}

La Comunidad de Madrid ha ido elaborando planes de acción para personas con discapacidad, de duración plurianual, en un recorrido que se remonta al año 1999. El paso del tiempo evidencia que las políticas públicas que tales planes incorporan han ido perfeccionándose y, por lo general, ganando en ambición, si bien también se detectan algunas deficiencias que, en planes futuros, convendría pulir.

25.- Una demanda de empleo es una solicitud de un puesto de trabajo por cuenta ajena realizada por una persona en edad laboral con el fin de insertarse o reinsertarse en una actividad laboral, o, si ya posee un trabajo, para conseguir otro o cambiar a uno mejor.

Para el cálculo del paro registrado se parte del total de los demandantes de empleo y se excluyen los colectivos relacionados en la O.M. de 11 de marzo de 1985 (BOE 14/03/1985).

Los datos de demandantes de empleo proceden del Sistema de Información de los Servicios Públicos de Empleo (SISPE), tomados a 31 de diciembre de 2014, o bien, a último día de cada mes objeto de estudio. 


\section{LA INSERCIÓN DE LAS PERSONAS CON DISCAPACIDAD EN EL EMPLEO PÚBLICO. ANÁLISIS JURÍDICO-ECONÓMICO DE LA SITUACIÓN EN LA COMUNIDAD DE MADRID}

De los tres planes realizados hasta el momento cabe destacar:

a) El primero (1999-2002), trató de establecer objetivos a medio plazo focalizándose más en el área de salud. Su logro más relevante se concretó en la aprobación de la Ley 11/2003, de 27 de marzo, de Servicios Sociales de la Comunidad de Madrid26.

b) El II Plan (2005-2008)27, más completo y mejor sistematizado, recogía diferentes áreas de acción. Siendo una de ellas la de empleo, de los cuatro programas que lo conforman sólo el primero ("Mejora de acceso al empleo de personas con discapacidad") recoge un objetivo centrado en la "Mejorar el acceso de las personas con discapacidad a la Función Pública", concretado en tres objetivos operativos:

a) Proponer una normativa de acceso de las personas con discapacidad a la función pública de la Comunidad de Madrid.

b) Proponer desarrollo de acciones positivas para mejorar el acceso de las personas con discapacidad a la Administración Regional y Local.

c) Realizar acciones formativas en materias relacionadas con la oferta de empleo público.

De todos ellos, el objetivo consistente en aprobar normativa fue el más fácil de cumplir a través del citado Decreto 54/2006 y que, en el momento de su aprobación, era más avanzado que la propia normativa estata|28.

c) El III Plan de Acción (2012-2015)29 se compone de ocho áreas de actuación con sus objetivos específicos y medidas correspondientes: 1) Atención social, dependencia, y promoción de la autonomía personal; 2) atención temprana; 3) salud; 4) educación; 5) empleo; 6) participación social; 7) trastornos del espectro autista; y 8) programas horizontales (en los que se incluyen temas como igualdad de oportunidades e inclusión social, mujer, calidad, innovación y excelencia, y accesibilidad universal)

26.- BOCM núm. 88, de 14 de abril de 2003.

27.- Disponible en: http://www.madrid.org/bvirtual/BVCM007014.pdf

28.- Vgr. situaba el cupo de reserva en un $6 \%$ (frente al $5 \%$ que establecía en aquel momento la normativa básica estatal), reservaba un $25 \%$ de las plazas del cupo de discapacidad a la discapacidad psíquica, y, en general, facilitaba una regulación del procedimiento que aportaba mayor seguridad jurídica.

29.- COMUNIDAD DE MADRID. III Plan de Acción para personas con discapacidad 2012-2015. Disponible en: http://www.madrid.org/bvirtual/BVCM007242.pdf 
En el capítulo de empleo, de los siete objetivos específicos, tres se relacionan con el empleo público. Son los que siguen, con sus respectivas actuaciones:

\begin{tabular}{|c|c|}
\hline OBJETIVOS ESPECÍFICOS & ACTUACIONES \\
\hline $\begin{array}{l}\text { 4. Adoptar medidas que faciliten y hagan realmente } \\
\text { efectiva la incorporación de las personas con } \\
\text { discapacidad al empleo público y en la contratación } \\
\text { temporal en la Administración Pública }\end{array}$ & $\begin{array}{l}\text { 4.1. Adaptar las pruebas de acceso al empleo público de las } \\
\text { personas con discapacidad } \\
\text { 4.2. Garantizar que en las convocatorias de empleo público se } \\
\text { establezcan cuotas de reserva para personas con discapaci- } \\
\text { dad, en los términos que indica la normativa en vigor }\end{array}$ \\
\hline $\begin{array}{l}\text { 5. Difundir e informar sobre las medidas que se } \\
\text { contemplan en la normativa actual para la } \\
\text { integración de personas con discapacidad en el } \\
\text { empleo público }\end{array}$ & $\begin{array}{l}\text { 5.1. En el empleo público establecer criterios generales y } \\
\text { orientativos sobre el concepto de ajustes razonables a la } \\
\text { hora de adaptar una plaza } \\
\text { 5.2. Impulsar las actuaciones que promuevan una mayor difusión } \\
\text { de las medidas existentes con objeto de garantizar el conoci- } \\
\text { miento, no sólo por las personas con discapacidad, sino } \\
\text { también por su entorno más inmediato (familiares, asociacio- } \\
\text { nes, etc.) }\end{array}$ \\
\hline $\begin{array}{l}\text { 6. Incrementar la presencia de las personas con } \\
\text { discapacidad intelectual en la Administración } \\
\text { Pública }\end{array}$ & $\begin{array}{l}\text { 6.1. Convocar plazas específicas para personas con discapaci- } \\
\text { dad intelectual en las Administraciones Públicas, siempre } \\
\text { que la normativa específica sobre empleo público lo permita }\end{array}$ \\
\hline
\end{tabular}

A diferencia de otros aspectos del Plan, el apartado relativo al empleo público peca de falta de ambición ya que parece limitarse el cumplimiento de la normativa vigente a lo que se añade un puñado de buenas intenciones. Si lo comparamos con el plan inmediatamente anterior, las diferencias no son importantes, lo que permite anticipar resultados poco halagüeños:

a) En primer lugar, las actuaciones que se ciñen a cumplir con las previsiones normativas son poco operativas, por cuanto el cumplimiento de lo establecido en leyes y reglamentos no es facultativo. Por poner un ejemplo: el cupo de reserva ha de respetarse con independencia de que ello venga o no contenido en un plan de acción. Por otro lado, la propia normativa madrileña se ha quedado desacompasada respecto de la ley básica estatal, sin que durante este tiempo hayan modificado las normas para proceder al necesario ajuste: si el Decreto 54/2006, de 22 de junio fue en su momento más avanzado que el EBEP, ahora ha quedado obsoleto. Como no puede ser de otro modo, ello no ha impedido que el $7 \%$ se haya aplicado en las Ofertas de Empleo Público de la $\mathrm{CAM}^{30}$.

30.- Véase, por ejemplo, Decreto 59/2014, de 8 de mayo, del Consejo de Gobierno, por el que se aprueba la Oferta de Empleo Público de la Comunidad de Madrid para el año 2014 (BOCM núm. 111, de 12 de mayo de 2014) y Decreto 41/2016, de 3 de mayo, del Consejo de Gobierno, por el que se aprueba la Oferta de Empleo Público de la Comunidad de Madrid para el año 2016 (BOCM núm. 107, de 6 de mayo de 2016).

Debe tenerse en cuenta que la falta de cumplimiento de la normativa básica estatal habría supuesto la nulidad de lo actuado.

CIRIEC-España, Revista de Economía Pública, Social y Cooperativa

ISSN: 0213-8093

№ 91/2017, pp. 203-234 


\section{LA INSERCIÓN DE LAS PERSONAS CON DISCAPACIDAD EN EL EMPLEO PÚBLICO. ANÁLISIS JURÍDICO-ECONÓMICO DE LA SITUACIÓN EN LA COMUNIDAD DE MADRID}

b) En segundo lugar, algunas de las actuaciones del plan carecen de la necesaria concreción y en tal medida, comprometen muy relativamente a la Comunidad de Madrid (sirva de ejemplo el punto 5.2). Al margen de la criticable vaguedad de la redacción, ese tipo de formulaciones plantea un problema adicional porque hace prácticamente inviable cualquier evaluación posterior de su cumplimiento.

c) En tercer lugar, el Plan no acomete aspectos relevantes del empleo público: las actuaciones no pueden poner sólo el foco en el acceso al mismo, sino que deberían también examinar las eventuales dificultades para progresar en la carrera administrativa, incluir la perspectiva de género, integrar las situaciones de discapacidad sobrevenida, cómo se atiende a las mismas, etc. En este sentido, el Plan responde a una perspectiva muy parcial y su contenido es pobre.

\subsection{El cumplimiento del Plan: análisis y conclusiones}

Habida cuenta de que el periodo de ejecución del Plan ha culminado, cualquier valoración sobre el mismo requiere el estudio de los datos. Surge aquí la primera dificultad relevante: desconociendo la posición de partida -esto es, cuántos empleados públicos con discapacidad tiene la Comunidad de Madrid-, se hace imposible comprobar la eficacia del Plan o si éste ha tenido algún efecto en los porcentajes totales.

Al realizar este trabajo se ha constatado la escasez de datos referentes a la situación de las PcD en el mercado de trabajo español. Esta insuficiencia se hace aún más evidente si queremos establecer algún tipo de comparación entre las distintas regiones que componen el territorio nacional ${ }^{31}$. Como era de esperar, esto no es diferente en lo que respecta a los datos referentes al empleo de las PcD en el Sector Público. Es por esto que para ofrecer una perspectiva del mismo a nivel regional se ha tenido que recurrir a la información ofrecida por los registros que tienen en cuenta todos los contratos realizados a PcD que se han registrado a lo largo de cada año al que se haga referencia en los Servicios Públicos de Empleo. 32

De este modo, en la Tabla 4 (Anexo) mostramos los datos correspondientes al número de contratos realizados a PcD en la Administración. Como se puede observar, a nivel nacional los contratos realizados a PcD en la Administración aumentaron entre 2009 y 2015, pero a un ritmo mucho más reducido que en el resto de actividades económicas. Así, mientras el número de contratos casi se duplico para el conjunto de actividades económicas, en la Administración apenas aumentaron un 25\%

31.- Los autores estiman que este es uno de los principales temas a abordar si se quiere avanzar en la integración de las personas con discapacidad en el mercado laboral español.

32.- Para el caso del empleo público, ya no es que no existan datos regionalizados sobre el número de PcD ocupadas o paradas, sino que tampoco existen datos acerca del número de personas contratadas cada año en la Administración. Es por esto que para aproximarnos a la evolución del empleo de las $P C D$ en el Sector Público hayamos tenido que explotar las cifras referentes al número de contratos realizados. Para ello, se suman los contratos mecanizados firmados por personas que han declarado su discapacidad en la demanda de empleo o lo han manifestado en el propio contrato. La explotación de datos se ha realizado a través del Sistema de Información de los Servicios Públicos de Empleo (SISPE). 
entre el comienzo y el final del periodo examinado. En la CAM las diferencias son aún más acentuadas, ya que los contratos realizados en la Administración no solo no aumentaron al mismo ritmo que los realizados en el conjunto de actividades económicas, sino que incluso se redujeron, pasando de los 467 de 2009 a los 279 de 2015.

Por lo tanto, a diferencia de la tendencia observada para el conjunto de la contratación, donde los contratos anuales realizados a PcD aumentaron sustancialmente entre el periodo 2009-2011 y el inmediatamente posterior -tanto para el total nacional como para la CAM- los contratos realizados a PcD en la Administración se redujeron a un ritmo de casi el 10\% para el total nacional (mucho más acentuado fue el efecto en la contracción que tuvo lugar en la CAM, donde el promedio anual de contratos se redujo un $51,3 \%$ ).

En cuanto a la importancia relativa que tienen los contratos a PcD en la Administración, de acuerdo a los datos que aparecen en la Tabla 5 (Anexo), parece ser que estos perdieron representatividad hasta 2012 donde alcanzaron su mínimo (1,96\% para el total nacional único año en que no se cumple la cuota de reserva y 1,34\% para la CAM) para luego ir recobrándola y terminar 2015 con cifras superiores a las del comienzo del periodo. Es significativo el caso de la CAM, donde el promedio de contratos a PcD sobre el total de contratos realizados para el periodo $2009-2011(1,85 \%)$ se redujo un 1,6\% respecto al del periodo $2012-2015$ de vigencia del Plan de acción (1,82\%). Por lo tanto, podemos concluir que en el periodo analizado no se cumplió la cuota de reserva en la CAM en lo que se refiere a contratos realizados (solo se cumplió en 2013 con un 2\% y 2015 con el 2,23\%).

De hecho, en el periodo analizado, en la CAM no solo perdieron importancia los contratos realizados a PcD sobre el total de contratos realizados en la Administración, sino que además se redujo el porcentaje que estos suponían sobre el total de actividades económicas (Tabla 6 en el Anexo). Así, en 2009 los contratos realizados a PcD en la Administración suponían el 3,86\% del total de contratos realizados a este colectivo y esta cifra se redujo hasta el 1,06\% en 2015 (una reducción del 67,8\% entre el promedio del periodo 2009-2011 y el del 2012-2015).

En resumen, en lo referente al número de contratos realizados a $\mathrm{PcD}$ podemos afirmar que mientras que para el conjunto de actividades económicas se experimentó un avance sustancial, tanto para el total nacional como para la CAM en particular, no ocurrió lo mismo en la Administración. De este modo, los contratos a PcD a nivel nacional en la Administración, pese a terminar 2015 con más contratos que 2009, redujeron su ritmo de crecimiento a lo largo del periodo. La situación del empleo de las PcD en la Administración en la CAM era aún peor, ya que el número de contratos realizados no solo redujo su crecimiento, sino que además en términos absolutos en 2015 aún no se habían recuperado las cifras alcanzadas en 2009 (como se ha señalado, debido principalmente a dos factores: por un lado, la pérdida de importancia de los contratos realizados a PcD en la propia Administración y por otro lado, la drástica reducción de los contratos realizados a PcD en la Administración respecto al resto de actividades económicas). 


\section{LA INSERCIÓN DE LAS PERSONAS CON DISCAPACIDAD EN EL EMPLEO PÚBLICO. ANÁLISIS JURÍDICO-ECONÓMICO DE LA SITUACIÓN EN LA COMUNIDAD DE MADRID}

En cualquier caso, la información obrante en el portal de transparencia de la CAM y los informes de evaluación (intermedia y final) del Plan ${ }^{33}$, permiten derivar conclusiones de interés:

a) Si atendemos a las tablas que el informe de evaluación final incorpora, tenemos 34 :

- De los 14 objetivos marcados en el apartado Empleo, 13 se han cumplido o iniciado y 1 no se ha iniciado (51), desarrollándose el mayor esfuerzo de ejecución en la primera mitad del periodo del plan (53).

- Entrando en el detalle del grado de cumplimiento de los objetivos, es el área de Empleo la que presenta un menor porcentaje de actuaciones en desarrollo o finalizadas (77\%) (56). Concretamente de las actuaciones, el 23\% no están iniciadas; el 10\%, iniciada; el 33\%, avanzada; el 31\%, cumplida; y 3\%, cumplida + (sic) (57). De cualquier modo, dichas actuaciones y porcentajes responden al área en su totalidad, abarcando, en suma, tanto las dirigidas al empleo en el sector privado como público.

- Tales cifras contrastan con el presupuesto ejecutado, que en esta área de empleo es del 166\% sobre el previsto (64). En este punto, destaca la partida relativa a subvenciones para el fomento del empleo de PcD en los centros especiales de empleo, cuya dotación ha ascendido a 130,6 millones de euros, representando el 5,6\% del gasto total ejecutado en el Plan (73).

- En cuanto a la valoración, algunas de las actuaciones evaluadas con mayor impacto se centran en el área de empleo, aunque sin distinguir el que se produce en el sector público. De hecho, la mayor parte de ellas (si no, todas) están orientadas al empleo fuera del entorno público: mejora de la percepción que el empresariado tiene de las $\mathrm{PCD}$, gracias a una labor de sensibilización y difusión de una imagen positiva de la discapacidad que se ha hecho en el marco de este Plan; o las acciones de formación para el empleo orientadas a estas personas teniendo en cuenta las necesidades específicas del mercado laboral... (80).

Este protagonismo del sector privado es lógico porque la capacidad de éste para generar empleo es mayor, centrando además la preocupación de los agentes consultados. No en vano, en el apartado en que se reseñan áreas u objetivos que se han echado de menos en el plan no hay referencia alguna al empleo público (87). Igualmente elocuente es que, de las trece páginas que el informe final dedica al empleo (pp. 166-178), las menciones a los objetivos sobre empleo público apenas ocupen media página y ninguna de las conclusiones. Así, se señala:

33.- Informe de evaluación intermedia:

http://www.madrid.org/cs/Satellite?blobcol=urldata\&blobheader=application\%2Fpdf\&blobheadername1=Content-

Disposition\&blobheadervalue1=filename\%3DInforme+Evaluaci\%C3\%B3n+Intermedia+Plan+BVCM013926.pdf\&blobkey=id\&blobtable=Mungo Blobs\&blobwhere $=1352901958671$ \&ssbinary $=$ true

Informe de evaluación final (2016):

http://www.madrid.org/cs/Satellite?blobcol=urldata\&blobheader=application\%2Fpdf\&blobheadername1=Content-

Disposition\&blobheadervalue 1=filename\%3DEvaluaci\%C3\%B3n+Final+del+Tercer+Plan+de+Acci\%C3\%B3n.+Publicamadrid.pdf\&blobkey=id \&blobtable=MungoBlobs\&blobwhere $=1352919371379 \&$ ssbinary $=$ true

34. - Las cifras entre paréntesis corresponden con la paginación en el Informe final. 
En las pruebas de acceso al empleo público se han seguido impulsando medidas de adaptación para las personas con discapacidad (como incorporación de intérprete de signos, tiempo adicional para realizar las pruebas, asistente personal, aumento de la letra del texto o ubicación específica del aula), así como mediante la incorporación de avances tecnológicos que se ponen a disposición de los aspirantes con discapacidad que así lo requieran (a título de ejemplo, software JAWS, ordenadores portátiles, etc.). (175)

Y en los aspectos a mejorar (177), se anotan los dos siguientes:

Sería deseable incrementar la presencia de las personas con discapacidad intelectual en la Administración Pública. (...)

Algunas actuaciones de esta Área no incorporan objetivos cuantificables o medidas concretas de ejecución, sino más bien una declaración de acciones genéricas.

b) En un trabajo anterior ${ }^{35}$ se constataba que las cifras generales aportadas por el portal de transparencia de la CAM van referidas a un periodo temporal (1 de enero de 2009 a 31 de marzo de 2016) que no permite un análisis preciso sobre los años de aplicación del Plan. Hoy este intervalo temporal se ha ampliado a marzo de $2017^{36} \mathrm{y}$, aunque terminado el plazo de ejecución de aquel, nos ofrece una tendencia que merece ser destacada.

No puede obviarse que el III Plan de Acción ha coincidido con años en los que la crisis económica ha supuesto un recorte importante en la oferta de empleo público en todas las Administraciones Públicas, incluida la $\mathrm{CAM}^{37}$. Así, en la Tabla 7 se puede observar la evolución de la oferta de empleo público desde el año 2005 hasta el año 2016.

Como se puede ver, la oferta de plazas en la Administración alcanzó su máximo en el año 2009, con 10.934 plazas, y después se redujo de forma sustancial en los años sucesivos, no recuperándose hasta el año 2015.

35.- Bengoechea, M.A., Burzaco, M., Carrillo, D., Colino, A., Ramos, J. y Rey, J.L., 2016: 46-47. 36.- Disponible en: http://www.madrid.org/es/transparencia/informacion-institucional/empleo-publico. 37.- $A$ AVV, 2015: 56-60. 


\section{Tabla 7. Evolución de la oferta de empleo público en la CAM (2005-2016)}

\begin{tabular}{|l|cccc|}
\hline & $\begin{array}{c}\text { Número de Plazas } \\
\text { Administración y Servicios }\end{array}$ & $\begin{array}{c}\text { Número de Plazas } \\
\text { Personal Docente }\end{array}$ & $\begin{array}{c}\text { Número de Plazas Personal } \\
\text { Instituciones Sanitarias }\end{array}$ & $\begin{array}{c}\text { Número Total } \\
\text { de Plazas }\end{array}$ \\
\hline 2005 & 1.553 & 1.485 & 1.857 & 4.895 \\
2006 & 0 & 2.550 & 1.054 & 3.604 \\
2007 & 3.142 & 2.000 & 2.220 & 7.362 \\
2009 & 837 & 4.955 & 5.142 & 10.934 \\
2011 & 156 & 489 & 0 & 645 \\
2012 & 0 & 190 & 0 & 190 \\
2013 & 69 & 380 & 0 & 449 \\
2014 & 262 & 212 & 150 & 624 \\
2015 & 702 & 660 & 801 & 2.163 \\
2016 & 1.364 & 1.500 & 1.043 & 3.907 \\
Total & 8.085 & 14.421 & 12.267 & 34.773 \\
\hline
\end{tabular}

FUENTE: Portal de transparencia de la CAM.

Si profundizamos un poco más en la información ofrecida por la propia CAM en su página Web y, referida al periodo que va desde el 1 de enero de 2009 hasta el 31 de marzo de 2017, podemos observar en la Tabla 8 la distribución del número de plazas convocadas por turno/cupo.

\section{Tabla 8. Distribución del número de plazas convocadas por turno/cupo (01/01/2009-31/03/2017)}

\begin{tabular}{|cccc|}
\hline $\begin{array}{c}\text { Número de Plazas } \\
\text { de Turno Libre }\end{array}$ & $\begin{array}{c}\text { Número de Plazas de } \\
\text { Promoción Interna }\end{array}$ & $\begin{array}{c}\text { Número de Plazas } \\
\text { Reservadas Cupo de Discapacidad }\end{array}$ & $\begin{array}{c}\text { Número de Plazas } \\
\text { Convocadas }\end{array}$ \\
\hline 4.006 & 774 & 256 & 5.036 \\
\hline
\end{tabular}

FUENTE: Portal de transparencia de la CAM.

De acuerdo a estas cifras, el número de plazas reservadas al cupo de discapacidad supuso un $5,08 \%$ del total de plazas convocadas, cifra esta muy inferior a la exigida por la normativa en vigor. Cabe destacar que este porcentaje es aún menor que el que reportábamos en nuestro informe de evaluación del III Plan de acción de la CAM con datos a 31 de marzo de 2006, donde este porcentaje se situaba en el 5,34\%. Por lo tanto, las acciones realizadas en el último año, no solo no han conducido a un acercamiento hacia las cifras indicadas en la normativa, sino que nos han alejado aún más del objetivo de incorporar a las $\mathrm{PcD}$ al empleo público. 
Una vez constatadas las carencias en términos de oferta de empleo público en general y, las PcD en particular, conviene examinar el lado de la demanda, para ver si se trata solo de un problema de falta de plazas en la Administración o si también se trata de un problema de falta de demanda de puestos por parte de las PcD. Así, en la Tabla 9 se presentan el número de solicitudes de participación en las convocatorias públicas de empleo de la CAM para el mismo periodo.

\section{Tabla 9. Solicitudes de participación (01/01/2009- 31/03/2017)}

\begin{tabular}{|ccccc|}
\hline $\begin{array}{c}\text { Número Global de } \\
\text { Instancias Presentadas }\end{array}$ & $\begin{array}{c}\text { Número Global de } \\
\text { Aspirantes Admitidos }\end{array}$ & $\begin{array}{c}\text { Número Global de } \\
\text { Aspirantes Excluidos }\end{array}$ & $\begin{array}{c}\text { No }^{\circ} \text { Aspirantes Admitidos } \\
\text { Cupo de Discapacidad }\end{array}$ & $\begin{array}{r}\text { N}^{\circ} \text { Aspirantes Excluidos } \\
\text { Cupo de Discapacidad }\end{array}$ \\
\hline 87.395 & 80.667 & 6.728 & 1.367 & 355 \\
\hline
\end{tabular}

FUENTE: Portal de transparencia de la CAM.

De acuerdo a estas cifras, en el último año solamente 2 aspirantes han sido admitidos dentro del cupo de discapacidad (1.367 comparados con los 1.365 de hace un año). Esto ha supuesto que, en relación al número global de instancias presentadas, su porcentaje baje hasta el 1,56\% (1,63\% hasta marzo de 2016) y, del mismo modo, también descienda su proporción en relación al número global de aspirantes admitidos, pasando de suponer un 1,77\% a representar un 1,70\% en 2017.

Otro dato que merece la pena destacar y, que emana de las cifras presentadas en la Tabla 9, es el elevado porcentaje que suponen los aspirantes excluidos del cupo de discapacidad sobre el número global de aspirantes excluidos. Así, pese a suponer solo un 1,70\% de los aspirantes admitidos, los aspirantes excluidos en el cupo de discapacidad constituyen el 5,28\% de los mismos. Además, los aspirantes excluidos representan el 20,62\% del total de aspirantes del cupo de discapacidad. Es decir, dentro del cupo reservado a las $\mathrm{PCD}$, uno de cada cinco aspirantes a acceder a un puesto en la Administración pública queda excluido en el proceso.

De este modo, de acuerdo a las cifras ofrecidas por la CAM, los aspirantes aprobados correspondientes al cupo de discapacidad (210) supusieron un 4,56\% del número global de aspirantes aprobados (4.601) entre enero de 2009 y marzo de 2017.

El examen de los porcentajes obtenidos permite concluir:

- Un elevado número de personas que se presentan al cupo de discapacidad son excluidos, sin que se conozcan exactamente las causas de exclusión más allá de no reunir los requisitos necesarios para concurrir a la convocatoria. Puede aventurarse que algunas de ellas se conectan bien con el incumplimiento de la condición de persona con discapacidad, bien con la falta de acreditación oportuna de alguno de dichos requisitos. En todo caso la ausencia de información no permite determinar con precisión tales causas, lo que podría ser relevante para diseñar medidas que eviten que se produzca esta circunstancia. 


\section{LA INSERCIÓN DE LAS PERSONAS CON DISCAPACIDAD EN EL EMPLEO PÚBLICO. ANÁLISIS JURÍDICO-ECONÓMICO DE LA SITUACIÓN EN LA COMUNIDAD DE MADRID}

- Resulta preocupante el porcentaje de aspirantes aprobados, que no llega al $5 \%$. Considerando el modo en que operan los sistemas de selección de los empleados públicos y los principios de mérito y capacidad, urge emprender acciones dirigidas tanto a la formación de los candidatos como a la posible reconsideración de las pruebas para las $\mathrm{PcD}$.

- La ausencia de información es prácticamente total cuando se investiga sobre las solicitudes de ajustes en las pruebas, de manera que se desconoce el número total de peticiones, los ajustes en su caso estimados y desestimados, la motivación del eventual rechazo a una petición de ajuste... Todo ello hace inviable evaluar las posibles actuaciones administrativas en uno de los objetivos del Plan, a priori menos dificultoso: debiendo solicitarse los ajustes correspondientes por el candidato, la normativa recoge pautas bastante regladas sobre ajustes de medios y de tiempos según discapacidad y grado de la misma38.

- La falta de información no permite saber si en el monto global hay PcD que se presentaron por turno libre (recordemos que una persona con discapacidad puede optar por presentarse en éste 0 a través del cupo de discapacidad). En cifras globales, tampoco se conoce a qué tipo de plazas aspiran, si hay cuerpos funcionariales en los que el cupo es inexistente dado que la discapacidad es prácticamente incompatible con las funciones que dichos cuerpos están llamados a desempeñar, los tramos de edad de los candidatos o la perspectiva de género. Todos estos extremos serían útiles para la confección del Plan plurianual que debería suceder al ya finalizado.

\section{Conclusiones}

Queda fuera de cuestión que las personas con discapacidad constituyen un colectivo vulnerable cuyos problemas están íntimamente ligados a las dificultades de acceso al empleo. Este trabajo se ha centrado en lo que afecta al sector público, siendo preciso separar adecuadamente los elementos implicados:

1) Como se ha puesto de relieve en trabajos previos $^{39}$, la discapacidad en el empleo público no puede circunscribirse al acceso al mismo y debe ser mucho más poliédrico integrando la carrera administrativa del empleado público (horizontal y vertical), derechos y deberes que componen su régimen estatutario, ajustes que exige el desempeño del puesto de trabajo, situaciones de discapacidad sobrevenida, etc.

38.- Véase, Anexo de la Orden PRE/1822/2006, de 9 de junio, por la que se establecen criterios generales para la adaptación de tiempos adicionales en los procesos selectivos para el acceso al empleo público de personas con discapacidad (BOE núm. 140, de 13 de junio de 2006). 39.- Martínez Hernández, 2009: 422 y ss. 
En este sentido, las normas españolas tienden a regular el acceso, pero olvidan estos otros extremos. Incluso las previsiones sobre los sistemas de selección tienden a limitarse a establecer el cupo de reserva y los ajustes de las pruebas, sin que haya habido planteamientos que avanzaran en soluciones distintas de las tradicionales. Un mal que, por otro lado, es común a otras legislaciones ${ }^{40}$.

Por otro lado, debería clarificarse definitivamente qué normas obligan a los distintos entes y organismos que entran dentro de la amplia noción de sector público y que, como hemos apuntado, se incumplen sistemáticamente.

2) En nuestra opinión los porcentajes relativos al cupo de reserva son idóneos y el problema en torno a los mismos no está tanto sobre el papel, cuanto en su aplicación efectiva. Siendo innecesario reiterar las cifras aportadas durante el trabajo, urge actuar sobre las causas toda vez que las convocatorias públicas tienden a cumplir, siquiera formalmente, con el cupo. Dicho esto, el paso decisivo pasa por conocer las razones que explican la falta de candidatos y, sobre todo, la ausencia de candidatos con la necesaria capacitación.

Sin embargo, la ausencia de información que pudiera dar pistas fiables de los motivos de los índices (altos en las exclusiones y bajos en los aprobados) impide también el diseño de políticas públicas adecuadas.

Evitando conjeturas arriesgadas, parece claro que nos hallamos ante problemas de formación e información:

- Si el acceso al empleo público pasa indefectiblemente por los principios de mérito y capacidad, las actuaciones deben situarse en el origen: dotar de capacidad, formación y mérito a las personas con discapacidad. En este sentido el logro de los objetivos sobre empleo requiere incorporar de manera imbricada la educación/formación y el empleo, buscando los cauces más idóneos según el tipo de discapacidad y valorando la posible conexión entre instrumentos formativos y acceso al empleo público (periodos de empleo temporal, pruebas específicas distintas a las del turno libre.... ${ }^{41}$.

Esto es aún más necesario en el caso de la discapacidad psíquica, como demuestra el hecho de que el art. 12 del Decreto 54/2006 contemple procesos selectivos específicos para las personas con discapacidad psíquica con origen en retraso mental.

Desde la doctrina se ha puesto de relieve, con acierto, que el sistema de acceso al empleo público plantea dificultades adicionales para las personas con determinadas discapacidades por el tipo de pruebas que suelen conformarlas (singularmente memorísticas), aunque probablemente el mayor hándicap se sitúe en el cumplimiento de los requisitos ligados a los títulos habilitantes que acreditan niveles de estudio y/o competencias profesionales ${ }^{42}$. 


\section{LA INSERCIÓN DE LAS PERSONAS CON DISCAPACIDAD EN EL EMPLEO PÚBLICO. ANÁLISIS JURÍDICO-ECONÓMICO DE LA SITUACIÓN EN LA COMUNIDAD DE MADRID}

- Aunque la concurrencia a un proceso selectivo constituye un acto voluntario, es esencial que haya una adecuada difusión más allá de la que propicie el diario oficial. La publicidad a través de Webs institucionales, asociaciones, agentes implicados en el sector, etc. son primordiales para lograr un conocimiento de las convocatorias y requisitos necesarios para solicitar la presencia en las mismas.

3) El estudio particular de la Comunidad de Madrid es de interés por su dilatada experiencia en planes de acción multisectoriales que han ido perfeccionándose a lo largo del tiempo. El esfuerzo que ello supone de racionalización y sistematización, de definición de áreas de actuación, objetivos y medidas merece, sin duda, una valoración positiva y es significativo que un $98 \%$ de los agentes implicados considere que el Plan es un instrumento idóneo para ordenar las políticas públicas sectoriales.

La clara mejora en la confección de los planes se torna menos plausible cuando se evalúa su eficacia y utilidad, más concretamente en relación con el empleo público:

- La ausencia de datos es un hándicap significativo en el que no vamos a abundar. Aunque también en este punto se advierte una mejora importante, la definición de las políticas públicas exige el análisis que permiten las cifras: sólo desde dicha realidad se pueden identificar las debilidades, perfilar convenientemente los objetivos y las actuaciones necesarias.

Recordemos que las políticas públicas se definen desde la discrecionalidad administrativa y que ésta, como ámbito de indiferencia jurídica relativa, comporta posibilidades de elección entre opciones igualmente válidas. La validez formal (el ajuste a la legalidad, en suma) debe cohonestarse con los requerimientos de eficacia y eficiencia que los arts. 103.1 y $31.2 \mathrm{CE}$, respectivamente, imponen al actuar de la Administración.

- La impresión que deja la lectura del Plan es que el empleo público se ha incluido porque es de aparición ineludible, pero su importancia es relativa (y escasa). Dejar buena parte de los objetivos en el mero cumplimiento de la normativa es insuficiente. $Y$ añadir actuaciones y fines genéricos, imposibles de evaluar con posterioridad, no aporta nada al plan ni a la consecución de resultados.

- El Plan se presenta en algunos casos excesivamente compartimentado. Según hemos señalado en la conclusión anterior algunos problemas ligados a la discapacidad requieren de actuaciones transversales. En este sentido, el origen de los problemas de acceso al empleo público está situado posiblemente en factores previos, señaladamente en la educación/formación. Los datos demuestran que el nivel educativo de las personas con discapacidad activas es significativamente inferior al de las personas sin discapacidad ${ }^{43}$, sin perjuicio de que, en la comparativa entre Comunidades Autónomas, la Comunidad de Madrid es la que presenta tasas más altas de educación superior ${ }^{44}$. 


\section{Bibliografía}

AAVV (2015): Libro blanco sobre acceso e inclusión en el empleo público de las personas con discapacidad, Madrid: INAP et al. Disponible en:

http://www.todostenemostalento.es/documents/333392/486410/LibroBlancoPcD.pdf (último acceso 11/09/2017).

BENGOECHEA, M.A., BURZACO, M., CARRILLO, D., COLINO, A., RAMOS, J. \& REY, J.L. (2016): El empleo de las personas con discapacidad en la Comunidad de Madrid. Análisis del impacto del III Plan de Acción de las personas con discapacidad de la Comunidad de Madrid (2012-2015). Disponible en: http://www.madridsinbarreras.org/wp-content/uploads/2017/01/INFORME-empleoIII-Plan.pdf (último acceso 14/07/17).

BURZACO SAMPER, M. (2016): Administración instrumental (2016). Disponible en: https://repositorio.comillas.edu/rest/bitstreams/70813/retrieve. DOI núm. 10.13140/RG.2.2.33410.48328.

CERMI (2011): Propuestas de modificación del Real Decreto 2271/2004, de 3 de diciembre, a fin de mejorar la normativa sobre acceso al empleo público de las personas con discapacidad, abril 2011. Consultado en: http://www.cermi.es/es-

ES/Novedades/Lists/Novedades/Attachments/1189/Propuestas\%20reforma\%20normas\%20acc eso\%20empleo\%20publico.doc

COMISIÓN EUROPEA (2010): Comunicación de la Comisión al Parlamento Europeo, al Consejo, al Comité Económico y Social Europeo y al Comité de las Regiones. Estrategia Europea sobre Discapacidad 2010-2020: un compromiso renovado para una Europa sin barreras \{SEC(2010) $1323\}$ \{SEC(2010) 1324\}. COM (2010) 636 final. Disponible en: http://eur-lex.europa.eu/legalcontent/ES/TXT/PDF/?uri=CELEX:52010DC0636\&from=ES (último acceso: 18 de julio de 2017).

COMUNIDAD DE MADRID (2012): III Plan de Acción para personas con discapacidad 2012-2015. Disponible en: http://www.madrid.org/bvirtual/BVCM007242.pdf

COMUNIDAD DE MADRID, CCOO, CEIM, UGT (2016): Estrategia Madrid por el Empleo 20162017. Disponible en:

http://www.madrid.org/es/transparencia/sites/default/files/plan/document/322_907_estrategia_m adrid_por_el_empleo_0.pdf

CORDERO GORDILLO, V. (2012): Régimen jurídico del empleo de las personas con discapacidad, Valencia: Tirant lo Blanch.

INSTITUTO NACIONAL DE ESTADÍSTICA (2015): Informe del mercado de trabajo de las personas con discapacidad estatal. 


\section{LA INSERCIÓN DE LAS PERSONAS CON DISCAPACIDAD EN EL EMPLEO PÚBLICO. ANÁLISIS JURÍDICO-ECONÓMICO DE LA SITUACIÓN EN LA COMUNIDAD DE MADRID}

MARTÍNEZ HERNÁNDEZ, A.J. (coord.) (2009): El empleo público y las personas con discapacidad, Madrid: CERMI.

MINISTERIO DE SANIDAD, SERVICIOS SOCIALES E IGUALDAD (2014): Plan de acción de la Estrategia Española sobre discapacidad 2014-2020 (aprobado por Acuerdo del Consejo de Ministros de 12 de septiembre de 2014). Disponible en: https://www.msssi.gob.es/ssi/discapacidad/docs/plan_accion_EED.pdf (última consulta 15 de julio de 2017).

MINISTERIO DE SANIDAD Y CONSUMO (2008): Estrategia Global de acción para el empleo de personas con discapacidad 2008-2012 (aprobada por Acuerdo del Consejo de Ministros de 26 de septiembre de 2008). Disponible en: http://www.empleo.gob.es/es/sec_trabajo/Estrategia_global_personas_discapacidad_2008_2012.pdf (última consulta: 19 de julio de 2017).

MORATALLA SANTAMARÍA, P. (2016): "Centros especiales de empleo", CIRIEC-España, Revista Jurídica de Economía Social y Cooperativa, 29, 235-272.

MURGUI, S. \& DASI, R.M. (2017): "El gasto público en discapacidad en la UE: estimación y análisis por culturas administrativas y modelos de Estado del bienestar", CIRIEC-España, Revista de Economía Pública, Social y Cooperativa, 89, 107-135.

OBSERVATORIO DE LA DISCAPACIDAD. MINISTERIO DE TRABAJO Y SEGURIDAD SOCIAL (2015): Informe Olivenza 2015. Disponible en: http://observatoriodeladiscapacidad.info/documentos/informe-olivenza/71-informe-olivenza-2015.html (último acceso 15 julio de 2017).

OBSERVATORIO DE LA DISCAPACIDAD. MINISTERIO DE TRABAJO Y SEGURIDAD SOCIAL (2016): Informe Olivenza 2016. Disponible en: http://observatoriodeladiscapacidad.info/attachments/article/90/Informe\%20Olivenza\%202016.pdf

ODISMET (Observatorio sobre Discapacidad y Mercado de Trabajo en España) (2016): Informe General 1. La situación de las personas con discapacidad en el mercado laboral, Madrid: Fundación ONCE. Disponible en: http://odismet.es/es/informes/.

ODISMET (2017): Informe General 2. La situación de las personas con discapacidad en el mercado laboral. Madrid: Fundación ONCE. Disponible en: http://odismet.es/es/informes/.

ORGANIZACIÓN IBEROAMERICANA DE SEGURIDAD SOCIAL (OISS) (2014): Medidas para la promoción del empleo de personas con discapacidad en Iberoamérica, Madrid: Ministerio de Asuntos Exteriores y Cooperación/OISS. Disponible en:

http://www.oiss.org/IMG/pdf/Oiss_Estudio_sobre_medidas_promocion_de_empleo-2.pdf (último acceso: 7 de septiembre de 2017)

OFICINA INTERNACIONAL DEL TRABAJO (2014): Lograr la igualdad de oportunidades en el empleo para las personas con discapacidad a través de la legislación. Directrices, Ginebra: OIT, $2^{a}$ ed. Disponible en: http://www.ilo.org/wcmsp5/groups/public/---ed_emp/--ifp_skills/documents/publication/wcms_322694.pdf (último acceso: 25 de agosto de 2017). 
PÉREZ PÉREZ, J. (2015): Contratación laboral de personas con discapacidad. Incentivos y cuotas de reserva, Madrid: Lex Nova/Thomson Reuters.

SANTERO, R., CASTRO, B., MARTíNEZ, I. \& GUILLÓ, N. (2016): "Integración de personas con discapacidad en la Economía Social. Elementos facilitadores y obstáculos detectados en la incorporación del colectivo", CIRIEC-España, Revista de Economía Pública, Social y Cooperativa, 88, 29-59.

TORRES LÓPEZ, M.A. (2011): La discapacidad en el Derecho Administrativo, Cizur Menor (Navarra): Civitas. 


\section{Anexo}

Tabla 3. Número de personas con discapacidad demandantes de empleo paradas y Tasa sobre el total de demandantes parados

\begin{tabular}{|c|c|c|c|c|c|c|c|c|c|c|c|c|c|c|c|c|c|c|}
\hline & \multicolumn{2}{|c|}{2009} & \multicolumn{2}{|c|}{2010} & \multicolumn{2}{|c|}{2011} & \multicolumn{2}{|c|}{2012} & \multicolumn{2}{|c|}{2013} & \multicolumn{2}{|c|}{2014} & \multicolumn{2}{|c|}{2015} & \multicolumn{2}{|c|}{$\begin{array}{c}2009-2011 \\
\text { Tasa Variación anual }\end{array}$} & \multicolumn{2}{|c|}{$\begin{array}{c}2012-2015 \\
\text { Tasa Variación anual }\end{array}$} \\
\hline & $\begin{array}{c}\text { Deman- } \\
\text { dantes } \\
\text { parados } \\
\text { con } \\
\text { discap. }\end{array}$ & $\begin{array}{l}\text { Tasa } \\
(\%)\end{array}$ & $\begin{array}{c}\text { Deman- } \\
\text { dantes } \\
\text { parados } \\
\text { con } \\
\text { discap. }\end{array}$ & $\begin{array}{c}\text { Tasa } \\
(\%)\end{array}$ & $\begin{array}{c}\text { Deman- } \\
\text { dantes } \\
\text { parados } \\
\text { con } \\
\text { discap. }\end{array}$ & $\begin{array}{c}\text { Tasa } \\
(\%)\end{array}$ & $\begin{array}{c}\text { Deman- } \\
\text { dantes } \\
\text { parados } \\
\text { con } \\
\text { discap. }\end{array}$ & $\begin{array}{c}\text { Tasa } \\
(\%)\end{array}$ & $\begin{array}{c}\text { Deman- } \\
\text { dantes } \\
\text { parados } \\
\text { con } \\
\text { discap. }\end{array}$ & $\begin{array}{c}\text { Tasa } \\
(\%)\end{array}$ & $\begin{array}{c}\text { Deman- } \\
\text { dantes } \\
\text { parados } \\
\text { con } \\
\text { discap. }\end{array}$ & $\begin{array}{c}\text { Tasa } \\
(\%)\end{array}$ & $\begin{array}{c}\text { Deman- } \\
\text { dantes } \\
\text { parados } \\
\text { con } \\
\text { discap. }\end{array}$ & $\begin{array}{c}\text { Tasa } \\
(\%)\end{array}$ & $\begin{array}{c}\text { Deman- } \\
\text { dantes } \\
\text { parados } \\
\text { con } \\
\text { discap. }\end{array}$ & $\begin{array}{l}\text { Tasa } \\
(\%)\end{array}$ & $\begin{array}{l}\text { Deman- } \\
\text { dantes } \\
\text { parados } \\
\text { con } \\
\text { discap. }\end{array}$ & $\begin{array}{c}\text { Tasa } \\
(\%)\end{array}$ \\
\hline idalucía & 16.811 & & 19.182 & 2,12 & 22.629 & 2,33 & 27.344 & 2,52 & 27.009 & 2,61 & 27.874 & & 28.690 & & 16,0 & 8,8 & 1,6 & 5,7 \\
\hline Aragón & 1.760 & 2,01 & 2.118 & 2,29 & 2.494 & 2,45 & 2.856 & 2,58 & 3.029 & 2,73 & 3.028 & 2,98 & 2.929 & 3,28 & 19,0 & 10,3 & 0,8 & 8,3 \\
\hline Asturias & 2.894 & 3,82 & 3.181 & 3,92 & 3.609 & 3,99 & 4.267 & 4,11 & 4.332 & 4,29 & 4.532 & 4,69 & 4.524 & 5,01 & 11,7 & 2,2 & 2,0 & 6,8 \\
\hline Balears, lles & 1.576 & 1,73 & 1.884 & 2,06 & 2.259 & 2,30 & 2.475 & 2,58 & 2.595 & 2,84 & 2.608 & 3,12 & 2.545 & 3,36 & 19,7 & 15,4 & 0,9 & 9,1 \\
\hline Canarias & 5.175 & 2,08 & 5.800 & 2,28 & 6.568 & 2,47 & 7.291 & 2,56 & 7.646 & 2,79 & 8.053 & 3,09 & 8.293 & 3,35 & 12,7 & 9,0 & 4,4 & 9,4 \\
\hline Cantabria & 1.353 & 3,20 & 1.513 & 3,43 & 1.672 & 3,39 & 1.951 & 3,46 & 2.128 & 3,74 & 2.139 & 4,24 & 2.291 & 4,63 & 11,2 & 3,0 & 5,5 & 10,2 \\
\hline Castilla y León & 5.279 & 2,90 & 5.703 & 2,93 & 6.119 & 2,94 & 7.282 & 3,07 & 7.709 & 3,27 & 8.147 & 3,66 & 8.051 & & 7,7 & 0,6 & 3,4 & 9,2 \\
\hline Cas.La Mancha & 3.752 & 1,99 & 4.434 & 2,16 & 5.385 & 2,38 & 6.673 & 2,54 & 7.239 & 2,87 & 7.656 & 3,23 & 7.809 & 3,55 & 19,8 & 9,3 & 5,4 & 11,8 \\
\hline Cataluña & 7.709 & 1,37 & 8.866 & 1,58 & 11.305 & 1,84 & 14.606 & 2,26 & 17.604 & 2,82 & 18.845 & 3,27 & 19.253 & 3,73 & 21,1 & 15,8 & 9,6 & 18,3 \\
\hline Com. Valenciana & 9.787 & 2,05 & 11.677 & 2,33 & 14.638 & 2,74 & 17.207 & 3,02 & 17.648 & 3,22 & 17.809 & 3,48 & 17.250 & 3,73 & 22,3 & 15,6 & 0,1 & 7,3 \\
\hline Extremadura & 2.992 & 2,66 & 3.448 & 2,88 & 3.888 & 2,87 & 4.191 & 2,87 & 4.415 & 3,04 & 4.382 & 3,11 & 4.397 & 3,38 & 14,0 & 3,8 & 1,6 & 5,6 \\
\hline Galicia & 6.579 & 2,95 & 7.279 & 3,07 & 7.958 & 3,08 & 9.197 & 3,30 & 9.299 & 3,43 & 9.278 & 3,68 & 9.284 & 4,06 & 10,0 & 2,2 & 0,3 & 7,1 \\
\hline Com. Madrid & 6.707 & 1,48 & 8.275 & 1,79 & 9.696 & 1,98 & 11.951 & 2,19 & 13.060 & 2,44 & 13.584 & 2,72 & 13.985 & 3,09 & 20,2 & 15,6 & 5,4 & 12,1 \\
\hline Murcia, Reg. de & 3.681 & 3,01 & 4.349 & 3,37 & 5.332 & 3,73 & 6.133 & 3,97 & 6.353 & 4,20 & 6.246 & 4,39 & 6.052 & 4,73 & 20,4 & 11,3 & $(0,4)$ & 6,0 \\
\hline Navarra & 641 & 1,58 & 765 & 1,78 & 877 & 1,87 & 989 & 1,90 & 1.083 & 2,10 & 1.190 & 2,49 & 1.226 & 2,84 & 17,0 & 8,8 & 7,4 & 14,3 \\
\hline País Vasco & 2.806 & 2,19 & 3.103 & 2,28 & 3.819 & 2,63 & 4.799 & 2,84 & 4.949 & 2,96 & 5.310 & 3,20 & 5.355 & 3,57 & 16,7 & 9,5 & 3,7 & 7,9 \\
\hline Rioja, La & 567 & 2,61 & 662 & 2,95 & 754 & 2,97 & 855 & 3,10 & 902 & 3,34 & 905 & 3,58 & 844 & 3,87 & 15,3 & 6,7 & $(0,4)$ & 7,7 \\
\hline Ceuta y Melilla & 853 & 5,10 & 1.006 & 5,31 & 1.157 & 5,46 & 1.447 & 5,83 & 1.441 & 5,79 & 1.516 & 6,00 & 1.621 & 6,58 & 16,5 & 3,5 & 3,9 & 4,1 \\
\hline Total & 80.922 & 2,06 & 93.245 & 2,27 & 110.159 & 2,49 & 131.514 & 2,71 & 138.441 & 2,94 & 143.102 & 3,22 & 144.399 & 3,53 & 16,7 & 9,9 & 3,2 & 9,2 \\
\hline
\end{tabular}

FUENTE: Elaboración propia con datos del Sistema de Información de los Servicios Públicos de Empleo. 
Tabla 4. Número de contratos a personas con discapacidad por Comunidades Autónomas (Administración)

\begin{tabular}{|l|ccccccccc|}
\hline & 2009 & 2010 & 2011 & 2012 & 2013 & 2014 & 2015 & $2009-2011$ & $2012-2015$ \\
\hline Andalucía & 2.916 & 2.946 & 3.070 & 2.359 & 3.684 & 4.299 & 6.571 & 2.977 & 4.228 \\
Aragón & 207 & 195 & 163 & 114 & 132 & 121 & 174 & 188 & 135 \\
Asturias, Principado de & 409 & 416 & 405 & 185 & 191 & 156 & 235 & 410 & 192 \\
Balears, lles & 202 & 232 & 175 & 60 & 61 & 98 & 131 & 203 & 88 \\
Canarias & 534 & 479 & 333 & 179 & 153 & 231 & 285 & 449 & 212 \\
Cantabria & 155 & 142 & 101 & 70 & 129 & 132 & 223 & 133 & 139 \\
Castillay León & 1.106 & 926 & 833 & 351 & 966 & 1.527 & 1.445 & 955 & 1.072 \\
Castilla-La Mancha & 1.889 & 1.980 & 1.464 & 723 & 816 & 964 & 1.346 & 1.778 & 962 \\
Cataluña & 682 & 890 & 544 & 342 & 325 & 507 & 686 & 705 & 465 \\
Comunitat Valenciana & 1.175 & 1.088 & 882 & 546 & 679 & 788 & 1.106 & 1.048 & 780 \\
Extremadura & 1.221 & 865 & 1.058 & 750 & 763 & 1.048 & 1.226 & 1.048 & 947 \\
Galicia & 598 & 531 & 479 & 320 & 363 & 461 & 619 & 536 & 441 \\
Madrid, Comunidad de & 467 & 381 & 378 & 137 & 192 & 188 & 279 & 409 & 199 \\
Murcia, Región de & 260 & 229 & 169 & 102 & 91 & 201 & 190 & 219 & 146 \\
Navarra, Comunidad Foral de & 89 & 94 & 91 & 98 & 89 & 109 & 146 & 91 & 111 \\
País Vasco & 223 & 203 & 156 & 103 & 86 & 135 & 147 & 194 & 118 \\
Rijoja, La & 38 & 32 & 25 & 23 & 14 & 17 & 16 & 32 & 18 \\
Ceuta & 211 & 145 & 102 & 78 & 163 & 69 & 82 & 153 & 98 \\
Melilla & 218 & 275 & 249 & 211 & 307 & 223 & 306 & 247 & 262 \\
Zona Extranjjera & & 3 & & & & & & 3 & \\
\hline Total & 12.600 & 12.052 & 10.677 & 6.751 & 9.204 & 11.274 & 15.213 & 11.776 & 10.611 \\
\hline
\end{tabular}

FUENTE: Elaboración propia con datos del Sistema de Información de los Servicios Públicos de Empleo. 
Tabla 5. Tasa Contratos realizados a PCD sobre total contratos en la Administración (porcentajes)

\begin{tabular}{|l|ccccccccc|}
\hline & 2009 & 2010 & 2011 & 2012 & 2013 & 2014 & 2015 & $2009-2011$ & $2012-2015$ \\
\hline Andalucía & 1,67 & 1,68 & 1,74 & 1,67 & 1,89 & 2,08 & 2,75 & 1,70 & 2,10 \\
Aragón & 2,07 & 2,13 & 1,86 & 1,78 & 1,85 & 1,64 & 2,10 & 2,02 & 1,84 \\
Asturias, Principado de & 4,12 & 4,93 & 5,41 & 3,82 & 3,58 & 3,34 & 3,75 & 4,82 & 3,62 \\
Balears, Illes & 3,12 & 3,69 & 3,27 & 2,21 & 2,49 & 3,34 & 4,13 & 3,36 & 3,04 \\
Canarias & 2,22 & 1,90 & 1,43 & 1,41 & 1,38 & 1,47 & 1,68 & 1,85 & 1,49 \\
Cantabria & 2,52 & 2,79 & 2,06 & 1,88 & 3,07 & 2,31 & 2,77 & 2,46 & 2,51 \\
Castilla y León & 3,90 & 3,83 & 3,40 & 2,58 & 4,97 & 6,87 & 5,81 & 3,71 & 5,06 \\
Castilla - La Mancha & 3,30 & 3,72 & 3,17 & 2,45 & 2,43 & 2,56 & 2,98 & 3,40 & 2,60 \\
Cataluña & 1,58 & 1,59 & 1,32 & 1,19 & 1,13 & 1,39 & 1,58 & 1,50 & 1,33 \\
Comunitat Valenciana & 3,18 & 3,03 & 2,75 & 2,46 & 2,87 & 3,01 & 3,49 & 2,99 & 2,96 \\
Extremadura & 2,81 & 2,15 & 2,60 & 2,22 & 1,99 & 2,42 & 2,71 & 2,52 & 2,33 \\
Galicia & 2,32 & 2,30 & 2,09 & 1,99 & 2,02 & 2,65 & 2,93 & 2,24 & 2,40 \\
Madrid, Comunidad de & 1,91 & 1,83 & 1,82 & 1,34 & 2,00 & 1,71 & 2,23 & 1,85 & 1,82 \\
Murcia, Regín de & 3,87 & 4,33 & 3,66 & 3,90 & 3,50 & 5,21 & 4,69 & 3,95 & 4,32 \\
Navarra, Comunidad Foral de & 1,78 & 1,97 & 1,94 & 1,96 & 1,69 & 1,81 & 2,11 & 1,90 & 1,89 \\
País Vasco & 2,03 & 1,77 & 1,56 & 1,52 & 1,42 & 1,54 & 1,47 & 1,79 & 1,49 \\
Rioja, La & 2,25 & 2,04 & 1,84 & 1,87 & 1,44 & 1,77 & 1,35 & 2,04 & 1,61 \\
Ceuta & 7,04 & 6,24 & 7,14 & 5,97 & 6,41 & 5,22 & 5,20 & 6,80 & 5,70 \\
Melilla & 8,70 & 10,93 & 11,35 & 12,18 & 13,04 & 9,01 & 9,84 & 10,33 & 11,02 \\
Zona Extranjera & 0,00 & 2,63 & 0,00 & 0,00 & 0,00 & 0,00 & 0,00 & 0,88 & 0,00 \\
\hline Total & 2,42 & 2,36 & 2,23 & 1,96 & 2,21 & 2,45 & 2,86 & 2,34 & 2,37 \\
\hline
\end{tabular}

FUENTE: Elaboración propia con datos del Sistema de Información de los Servicios Públicos de Empleo. 
Tabla 6. Tasa contratos realizados a PcD en la Administración sobre Total Actividades Económicas (porcentajes)

\begin{tabular}{|l|ccccccccc|}
\hline & 2009 & 2010 & 2011 & 2012 & 2013 & 2014 & 2015 & $2009-2011$ & $2012-2015$ \\
\hline Andalucía & 9,89 & 9,37 & 9,57 & 7,53 & 10,01 & 10,27 & 13,33 & 9,61 & 10,28 \\
Aragón & 5,81 & 4,71 & 4,02 & 2,85 & 3,19 & 2,49 & 3,08 & 4,85 & 2,90 \\
Asturias, Principado de & 5,40 & 5,14 & 5,29 & 2,54 & 2,56 & 1,92 & 2,35 & 5,28 & 2,34 \\
Balears, llles & 7,77 & 8,59 & 6,07 & 2,12 & 1,75 & 2,45 & 2,62 & 7,48 & 2,24 \\
Canarias & 11,92 & 10,35 & 6,77 & 3,53 & 2,86 & 3,44 & 3,62 & 9,68 & 3,36 \\
Cantabria & 6,92 & 5,86 & 4,32 & 3,06 & 5,09 & 4,11 & 5,47 & 5,70 & 4,43 \\
Castillay León & 13,51 & 10,68 & 9,58 & 4,62 & 10,06 & 12,83 & 10,56 & 11,26 & 9,52 \\
Casilla-La Mancha & 27,11 & 25,27 & 19,44 & 10,67 & 10,02 & 9,76 & 11,03 & 23,94 & 10,37 \\
Cataluña & 4,27 & 4,76 & 2,87 & 1,82 & 1,52 & 1,91 & 2,07 & 3,97 & 1,83 \\
Comunitat Valenciana & 9,32 & 7,71 & 6,38 & 3,95 & 4,42 & 4,40 & 5,06 & 7,80 & 4,46 \\
Extremadura & 21,93 & 15,71 & 18,38 & 13,08 & 11,90 & 13,88 & 14,06 & 18,67 & 13,23 \\
Galicia & 6,72 & 5,56 & 5,00 & 3,73 & 3,78 & 3,92 & 4,33 & 5,76 & 3,94 \\
Madrid, Comunidad de & 3,86 & 2,67 & 2,25 & 0,82 & 1,05 & 0,84 & 1,06 & 2,93 & 0,94 \\
Murcia, Región de & 4,75 & 4,13 & 2,95 & 1,75 & 1,29 & 2,35 & 1,84 & 3,95 & 1,80 \\
Navarra, Comunidad Foral de & 5,89 & 5,17 & 4,89 & 5,73 & 3,93 & 4,12 & 4,85 & 5,32 & 4,66 \\
País Vasco & 2,66 & 2,15 & 1,51 & 1,07 & 0,81 & 1,11 & 1,04 & 2,11 & 1,01 \\
Rioja, La & 3,31 & 2,80 & 2,03 & 2,02 & 1,08 & 0,96 & 0,73 & 2,71 & 1,20 \\
Ceutaa & 39,59 & 26,61 & 20,82 & 23,35 & 37,21 & 19,38 & 21,81 & 29,00 & 25,44 \\
Melilla & 27,81 & 32,28 & 30,89 & 25,21 & 31,68 & 25,17 & 32,97 & 30,33 & 28,76 \\
Zona Extranjera & 0,00 & 14,29 & 0,00 & 0,00 & 0,00 & 0,00 & 0,00 & 4,76 & 0,00 \\
\hline Total & 9,12 & 7,96 & 6,87 & 4,49 & 5,38 & 5,55 & 6,26 & 7,98 & 5,42 \\
\hline
\end{tabular}

FUENTE: Elaboración propia con datos del Sistema de Información de los Servicios Públicos de Empleo. 